\title{
Sea Urchins as an Inspiration for Robotic Designs
}

\author{
Klaus M. Stiefel ${ }^{1,2,3}$ and Glyn A. Barrett ${ }^{3,4, *(D)}$ \\ Neurolinx Research Institute, La Jolla, CA 92039, USA; klaus@neurolinx.org \\ 2 Marine Science Institute, University of the Philippines, Dilliman, Quezon City 1101, Philippines \\ 3 People and the Sea, Malapascua, Daanbantayan, Cebu 6000, Philippines \\ 4 School of Biological Sciences, University of Reading, Reading RG6 6UR, UK \\ * Correspondence: glyn.barrett@reading.ac.uk; Tel.: +44-(0)-118-378-8893
}

Received: 25 August 2018; Accepted: 4 October 2018; Published: 10 October 2018

check for updates

\begin{abstract}
Neuromorphic engineering is the approach to intelligent machine design inspired by nature. Here, we outline possible robotic design principles derived from the neural and motor systems of sea urchins (Echinoida). Firstly, we review the neurobiology and locomotor systems of sea urchins, with a comparative emphasis on differences to animals with a more centralized nervous system. We discuss the functioning and enervation of the tube feet, pedicellariae, and spines, including the limited autonomy of these structures. We outline the design principles behind the sea urchin nervous system. We discuss the current approaches of adapting these principles to robotics, such as sucker-like structures inspired by tube feet and a robotic adaptation of the sea urchin jaw, as well as future directions and possible limitations to using these principles in robots.
\end{abstract}

Keywords: bionic engineering; bioinspired robots; neuromorphic systems; neuromorphic engineering; echinoderm; sea urchin; robotics; distributed control

\section{Echinoderm Motor and Nervous Systems and How They Could Inspire Robotics}

Phylum Echinodermata is composed of the sea stars (Asteroidea), sea cucumbers (Holothuria), brittle stars (Ophiuroidea), feather stars (Crinoidea), and sea urchins (Echinoidea). All species within this phylum, apart from several predatory Asteroidea, are passive and highly efficient marine filter feeders, algal grazers, or detritivores [1,2]. Members of the Echinoidea have evolved a number of very interesting anatomical and neurobiological features, which we believe could inspire novel robotic designs. To illustrate this point, we will first outline some of the interesting neural and motor systems of echinoids, and how these affect, influence, and drive behavior. Specifically, we will elaborate on the physical properties of their central nervous system, tube feet, spines, catch apparatus, pedicellariae, and covering behavior. We will then summarize the general principles which emerge from the study of the nervous and locomotory systems of sea urchins. Next, we will outline the few, but very interesting existing robotic approaches inspired by echinoderms in general (sea urchins, sea stars, brittle stars, and sea cucumbers), and possible approaches to robotics inspired by sea urchins not yet implemented. Finally, we will discuss possible limitations of echinoid-inspired robotic designs.

Owing to a lack of general research in echinoderm biology, sea urchins being of a particularly low priority, not all the work discussed in this article was conducted on sea urchins. Previous studies, especially pertaining to the central nervous system, have mostly been conducted on sea stars and sea cucumbers. However, due to the phylogenetic relatedness to their echinoid cousins, we will still discuss these studies as any findings are likely to translate across phyla.

\subsection{Central Nervous System}

Whilst echinoids possess a rudimentary central nervous system, it is much less centralized compared to that of highly cephalized animals, including all vertebrates and many invertebrates. They 
possess no centralized brain, to which all sensory input converges, and from which motor commands emerge, as it has evolved convergently in vertebrates and insects [3]. The most centralized structure echinoderms possess is the circumoral nerve ring, a ring of neuron cell bodies and fibers which encircle the mouth. Emerging from this nerve ring are five radial nerves, which project up towards the dorsal pole of the animal in the sea star [4] and sea cucumber [5]. The five-fold symmetry seen in the echinoid nervous system is a consequence of the five-fold symmetry inherent to all echinoderm body plans, which topologically sets them apart from all other phyla and has involved massive re-organization of developmental gene networks [6-8]. Some of the five-fold symmetry was secondarily lost in a single evolutionary echinoid lineage leading to the more advanced, irregular sea urchins, the "sand dollars" and their relatives [9-11]. Along the way, the radial nerves connect to a network of nerves covering the whole sea urchin body surface, the basiepithelial nerve plexus. Despite the evolutionary position of the echinoderms as a sister group of the chordates in the Deuterostome clade (which includes vertebrates), this rather simple nervous system should not be regarded as primitive, yet in fact it is a highly efficient regulatory machine [12].

The nervous system of echinoids and other echinoderms is separated into an ectoneural and a hyponeural nervous system [5], an arrangement unique to this phylum. The ectoneural nervous system seems to be derived from the ectodermal germ layer, as is the case in all other animals. The separate hyponeural nervous system seems to be derived from the mesoderm (as are the muscles). It is likely that the prominent skeletal plates of echinoderms (especially of sea urchins, the tests) have made it difficult for the "regular" ectoneural nervous system to reach the muscles, which necessitated the evolution of a second nervous system. The circumoral nerve ring in sea cucumbers is only ectoneural, whilst the radial nerves have ecto- and hypo-neural parts [5]. Some limited connections between the two nervous systems exist. A third nervous system, the enteric nervous system, innervates the echinoderms' intestines. Genomic analysis has shown that echinoids lack the genes for the proteins composing gap junctions between neurons, as well as the cannabinoid, lysophospholipid, and melanocortin receptors, crucial components of important messenger systems in vertebrates [13].

The radial nerves in the sea cucumber have been investigated in detail. A variety of neurochemical markers including Pax6, Calbindin, PH3, GABA, GFSKLYFamide, TH, and PH3 identify distinct regions of the endo- and ecto-neural parts of the radial nerve fibers. The radial nerves are composed of distinct sub-systems located in different parts of the sea cucumber body [14]. While the echinoderm central nervous system is not centralized, and rather simple on a gross morphological level, it is nevertheless complex on a neurochemical level. This neurochemical specialization might be more pronounced in holothurians, with their compressible bodies, than in the rigid-bodied echinoids [14]. The basiepithelial nerve plexus of the sea urchin Centrostephanus longispinus contains strands of nerve fibers measuring between 0.1 and $2.0 \mu \mathrm{m}$ in diameter, originating from multipolar neurons [15]. Several echinoderm nervous systems also possess diverse types of glial support cells, with the largest population of glial cells resembling vertebrate radial glia $[5,16]$.

The echinoderm central nervous system is indeed far from simple in terms of its microscopic architecture and molecular composition, but nevertheless is much less complex in its overall topology and large-scale organization. What can an organism with no centralized brain and no central point of integration of sensory inputs achieve? To answer this question, we will now look at the functioning and coordination of echinoids' appendages, followed by a review of some aspects of echinoid behavior.

\subsection{Tube Feet and Their Nervous Control}

A unique feature of echinoid, holothurid, and asteroid bodies are the tube feet, which are more prominent in sea urchins. These appendages form part of the echinoid's hydraulic (ambulacral) system with each tube foot acting semi-autonomously [17]. Tube feet are filled with water pumped in from the surrounding environment and held under hydrostatic pressure through a series of interconnecting valves and channels. The principal role of tube feet is in underwater adhesion to substrate for stability and mobility, and to prey for nutrient acquisition [18]. 
Tube feet move through a coordinated system of longitudinal and radial muscles. On the distal end of the tube foot sits a suction disc, which can attach itself to surfaces with the use of another set of muscles. In the sea star Asterias rubens, the force per unit area exerted by a tube foot was measured at about 0.2 MPa [19]. Differing attachment forces of the tube feet of several sea urchin species were measured in one study with Arbacia lixula, Paracentrotus lividus, and Sphaerechinus granularis exhibiting $0.05-0.09 ; 0.11-0.29$, and $0.1-0.2 \mathrm{MPa}$, respectively [20]. Tube feet are thought to have evolved from respiratory organs and other gaseous diffusion systems [21], and are also thought to be involved in photosensory signal transduction through the presence of vertebrate-type opsins and PAX6 [22]. Dependent on species and size of individual, hundreds to thousands of these multifunctional, mechano-sensory, adhesive organs are found on the body surface of sea urchins.

In sea cucumber, tube feet are connected to the ectoneural nervous system plexus, and contain local nerve fibers and cells with the terminal disc being particularly heavily innervated [23]. The disc also contains cells which secrete an adhesive substance (a mixture of lipids, carbohydrates, and proteins) useful in attachment to and manipulation of objects [24]. Tube feet function is further augmented by the presence of connective tissue with plastic mechanical properties [25] and are covered with chemoreceptors [26]. However, chemoreception in the deep sea urchin Stylocidaris lineata appears to be played out only via direct contact of the tube feet with objects in the environment, and any open space between the two appears to nullify sensory stimuli [27]. Therefore, in this species, tube feet can be considered organs of taste and not of smell.

Very interesting recent studies indicate that the terminal discs of the tube feet act as photoreceptors. Pax6 and opsin genes, which in vertebrates are expressed in the eye, are similarly expressed in the discs [28,29]. Skeletal elements behind the Pax6 containing cells shade them and provide a sense of direction. This arrangement of a limited number of light-sensitive cells without lenses results in a low-resolution image, but in a perception of the visual field at low acuity. One study found a visual acuity of about $10.6^{\circ}$ in the sea urchin Diadema setosum [30]. Since the tube feet are motile, they can move the disk in different directions and sense light levels from all directions. It is not known, however, if echinoids actually use this process for directional vision.

Sea urchins, as a whole, are generally somewhat photophobic, and move away from light sources, with individuals of many species crawling towards crevices and dark hiding places during the day (personal observation). Since there is little evidence of other photosensitive organs known in the sea urchin, this photophobic behavior is likely due to an integration of the signals provided by the tube feet, as well as the spines and pedicellariae, which are also sites of both c- and r-opsins [28]. A subsequent integration of these signals by the nervous system, likely determines the direction of movement for the whole animal. As control of the muscular and nervous systems appears to be closely integrated, tube feet are likely capable of mechano-reception, and sense any external force applied to their disc. This is also confirmed by behavioral observations, as tube feet attached to an object release their grip once the force pointing away from the sea urchin passes a certain threshold [25].

This type of neuro-anatomy is consistent with an integration of local signals with a coordinated global signal, originating in and going to the sub-epidermal ectoneural nervous system. The tube feet constitute a local element integrating chemo-sensory, photo-sensory, and mechano-sensory input, with motor output. Interestingly, tube feet function independently from the main body if a small part of the echinoid skin is excised from the animal [31]. The neurotransmitter GABA acts to excite the cholinergic motor neurones of the tube feet. Acetlycholine, via muscarinic and nicotinic receptors, activates the tube feet's muscles [32]. 


\subsection{Spines and Their Nervous Control}

These are the iconic organs of sea urchins, by which the animals are recognized. Whilst the spines provide a defensive function, they are much more than immobile passive thorns. Sea urchins have the ability to move their spines, and orient them towards any perceived threat. Threats are sensed by the sea urchin, either via photosensitive receptors or through mechano-reception. Spine-induced-photosensory-perception likely stems from signal transduction from the tube feet, whereas the spines themselves are sensitive and react accordingly to physical stimuli.

Nerve fibers run along the length of the spines. In Diadema antillarum, 2-5 msec wide $\mathrm{Ca}^{2+}$ action potentials, produced by a set of 14-21 bundles of neurites of $~ 1000$ processes near the spine base and tapering towards the spine tip were measured [33]. At the spine base, a basal nerve ring encircles the spine and contains the somata of neurons and nerve fibers [34]. These spines control the muscles orientating the spines, and the catch apparatus as described below.

\subsection{Catch Apparatus}

The catch apparatus is composed of a type of contractile connective tissue and sits at the base of the echinoid spines but is also present in tube feet stems [35]. The catch apparatus consists of catch connective tissue, mutable collagenous tissue that shows large changes in stiffness [25]. These changes are brought about by the activation of specialized proteins, tensilins, triggered by calcium influx and modulated by peptides (shown in sea cucumbers which regulate body stiffness with catch tissue [36,37]). This system seems to be under nervous control, as demonstrated in sea urchin spine [38] and sea cucumber body wall [39]. A mechanical division of labor takes place in the sea urchin spine: the spine muscles are responsible for spine movements and the catch apparatus for maintenance of spine posture [38]. This unique connective tissue is somewhat reminiscent of shape-memory alloys [40], which could be used in robotic implementations of echinoids.

\subsection{Pedicellariae}

An additional type of echinoid appendage is the pedicellariae, closely resembling stalked claspers. Evolutionarily, the pedicellariae are derived from spines and come in several classes. These appendages serve various functions, including a physical defense against threats, a cleaning mechanism through the surface scraping and shedding of microbial biofilms and larger parasites, and in injecting venom into would-be predators [41]. The venom of some species (e.g., Toxopneustes sp.) is known to cause serious bodily damage in humans. The pedicellariae seem exclusively defensive in function and are not involved in the covering behavior as mentioned below. Similarly, to tube feet, pedicellariae maintain function for some time even following excision from the main echinoid body. Pedicellariae range in size from less than $100 \mu \mathrm{m}$ to several $\mathrm{mm}$.

\subsection{Nervous Control of Pedicellariae}

The spine-derived pedicellariae contain their own set of tactile sensors, nerves, and opening and closing muscle complexes. The jaws of the pedicellariae are covered in cilliated cells which are connected to the axons of neurons in the pedicellaria $[42,43]$. Behavioral observations indicate a certain amount of coordination between neighboring pedicellariae, whereby activation of one prevents the closure of its neighbor's jaws. 


\subsection{Non-Centralized Nervous Control}

The principle which emerges from the study of echinoid locomotion and behavior is that of non-centralized, locally integrated perception and motor control, with limited central coordination. Each tube foot, spine, or pedicellaria independently senses its environment (with tactile sensing in all appendages, and chemo-sensory and photoreception in tube feet), then reacts and acts based on this information. The appendages also send information about their states via the subdural nerve plexus, where it further converges onto the radial nerves and the circumoral nerve ring. On the level of the subdural nerve plexus, each appendage can recruit neighboring appendages for coordinated action, e.g., several pedicellariae might consolidate a group attack against a parasite. On the level of the radial nerves and the circumoral nerve ring, the behavior of the entire animal is determined as one. For example, a noxious stimulus on one side can cause the sea urchin to mobilize its appendages in a concerted effort for escape. Via the integration of local signals, the sea urchin can also act as one large eye, integrating the light signals from all its light-sensitive tube feet [28].

The investigative work of Bullock and Smith, since the 1960s, has already revealed good information on the non-centralized nervous system of echinoids [44,45]. Experimentally, they found that the spine convergence response only spreads on the surface of the animal along straight lines, and is not dependent on the presence of the central nervous system. In simulations, they found that such a type of propagation can occur in a sparsely connected network with rather precisely adjusted firing thresholds for each neuron, an adjustment which could happen during the ontogenetic development of each sea urchin. Their work shows that the model of coordinated action of semi-independent sensory-motor units, as outlined above, is quantitatively possible.

\subsection{Covering Behavior}

An intriguing behavior shown by a number of phylogenetically distant sea urchins, is to cover themselves with debris picked up from their environment [46,47]. Spines and tube feet act together to select covering material and to transport it from the sea-bed up and onto the body of the animal (Figure 1). Different species of echinoids use different types of covering materials, including plant material, coral rubble, and calcium carbonate based shell fragments $[48,49]$. Some species drop these fragments at night and collect other fragments the next day. This shows that the animals are going through a decision-making process involving the covering material, as opposed to passively and unselectively transporting any material found in their environments onto their body surfaces. Anti-predatory function [50], UV protection [51,52], and weighing down in the face of water movement [51] have been shown to be effective reasonings for this covering behavior. Food storage may be another reason for this behavior, as several species prefer to cover themselves with sea-grass or rodolith algae. Microalgae is known to grow epiphytically on seagrass especially [53], and sea urchins have been recorded transporting the fragments down their bodies and towards the oral surface of their test. 


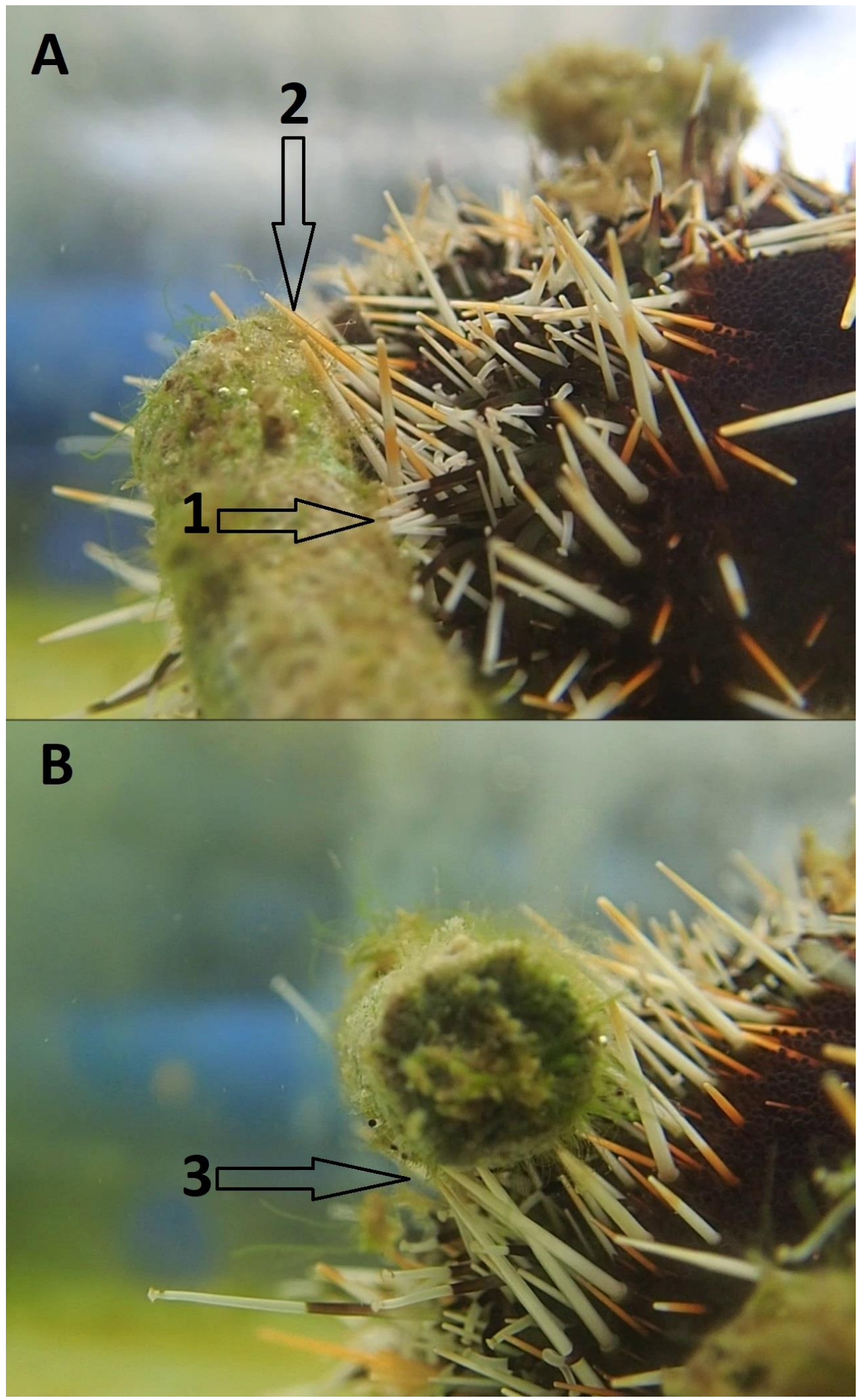

Figure 1. Coordinated activity of spines and tube feet in the covering behavior of Salmacis sphaeroides. (A) A piece of coral rubble is lifted onto the dorsal surface of the sea urchin. Arrow \#1: A group of 6 tube feet pulls the fragment upwards, while the spines above the fragment turn sideward to avoid blocking the path of the fragment (arrow \#2). (B) Several seconds later, the coral fragment has moved upward. From below, spines support it and push it further dorsally (arrow \#3). 
This behavior is ecologically very interesting, and has been deemed as tool use by some workers in the field [49]. From the point of view of a roboticist, the covering behavior shows that a collection of semi-independent sensory-motor elements can collaborate to enable a complex type of behavior, i.e., tool use, believed to be unique to humans until a few decades ago [54]. Robots inspired by sea urchin anatomy and neurobiology need not be restricted to simple crawling and obstacle avoidance. It will (at least in principle) be possible to use such robots for more sophisticated tasks.

\section{Current Echinoderm-Inspired Robotics}

A limited number of very interesting approaches have been attempted to build robots inspired by echinoderm bodies. One group built a soft-bodied robot replicating the crawling motion of sea stars [55]. Sea stars use a gait involving all five of their arms for walking. They possess tube feet similar to those of sea urchins but use them to gain traction when walking with their arms, not as primary modes of locomotion as the sea urchins with their inflexible skeletons do. Fuzzy Q-learning was used to find an appropriate gait for a sea-star inspired multi-legged robot [56]. Brittle stars use a similar arm-based mode of locomotion, used as an inspiration for robotics [57]. This robot used coupled dynamical systems to coordinate the arms.

A different, equally interesting, locomotion principle is used by another echinoderm group, the sea cucumbers. These worm-shaped animals use peristaltic motion of their bodies to crawl, and can pass through constrictions narrower than their average body diameter. One study implemented a crawling mechanism similar to the one seen in sea cucumbers in a robot [58]. Other studies have resulted in: (1) The design and manufacture of a magnetically-controlled crawling mechanism based on tube feet [59]; (2) the design and testing of an echinoderm tube feet inspired suction device with an improved performance in holding onto rough surfaces, together with a quick release mechanism [60]; and (3) the creation of a sea urchin inspired robot, capable of traversing irregular surfaces [61].

Whilst there are certainly several very interesting studies, with a focus on sea urchins as inspirations for developments in robotics, the field is still most certainly in its infancy. There remain very promising avenues of research to pursue, and principles of sea urchin functioning to be implemented.

\section{Interesting Principles from Sea Urchins to Adapt in Robotics}

The idea of neuromorphic engineering is not to replicate an entire animal, but to adopt the most interesting principles of the neural functioning of that animal for engineering purposes. We believe that there are a number of principles in sea urchin physiology and body function which could inspire the design of novel robots (Table 1). First and foremost, this is an integration of miniaturized sensors of several sensory modalities, together with a motor system. The integrated sensory-motor units found in sea urchins are highly modular, and hence are scalable, where going from a robot with 100 to one with 1000 such units will not necessitate a fundamental re-design.

Another advantage will be the limited neural circuitry necessary to coordinate the local motor units. In animals with a highly centralized nervous system, like vertebrates or insects, a great amount of information converges on the brain and is processed there in highly complex nervous structures, involving interneurons with many synapses removed from sensory input and motor output. As a consequence, it is not always clear what the activity of these interneurons represents, which is a challenge both in neurobiology and in neuromorphic engineering hoping to draw inspiration from neurobiology. As an example, the neurons in higher sensory cortical areas of primates respond to vision, audition, and to a number of feature combinations in both of these sensory domains [62-64]. It is not completely clear what the precise inputs and outputs to these neurons (and brain regions) are, but they must be composed of sensory input, reverberatory activity originating in the same or in connected brain structures, and in activity based on memories. The occurrence of synchronized oscillations, relevant for information processing [65] in mammalian brains complicates this issue further. Neurons in higher brain areas of mammals are removed in multitudes from both the sensory 
input and the motor output by multiple synapses, and it is often unclear what the activity of these neurons represents.

This problem is alleviated if we only need to deal with a small neuronal network, which directly links sensory input to behavior, with only one level of interneurons and few synapses in-between. This is the case in the neural elements of the tube feet, spines, and pedicellariae. We know what these neurons encode and represent, and where their output goes. Understanding such a small neural system will be simple and implementing it in a robot will be much simpler, compared to a robot controller inspired by a mammalian brain. This distinct lack of neurons, as compared to highly cephalized organisms, and its entire nervous system made up of only hundreds of neurons should not automatically make us consider sea urchins as primitive. Once we assemble and coordinate hundreds of these semi-independent sensory-motor units, complex coordinated behaviors can ensue, as described in the covering behavior outlined above.

Only a limited central coordination is necessary to produce goal-directed emergent behavior for the whole animal from the activities of the multiple local sensory-motor units. In the sea urchin, this coordination is implemented by a nerve net and a central nerve ring. Since only a small amount of data is transferred between units, this could be done wirelessly in robots, and many independent units could coordinate, even if not physically connected. Several physically separate sea urchin robots connected in this manner would act as one functional entity.

A big advantage of a decentralized-modular body plan is that it shows graceful degradation. Sea urchins continue to operate and thrive even if some of their tube feet, spines, or pedicellariae are damaged, and a similar behavior when damaged would be beneficial in sea urchin-inspired robots. In fact, echinoderms are excellent at recovering when body parts are removed, with designated break-points present on their bodies [66].

Current approaches to marine robotics concentrate on navigation and autonomous operation, mostly of torpedo- or platform-shaped automated vehicles. However, due to the remoteness of the locations that these robots operate in and difficulties in wireless signal transmission in water [67], both autonomy as well as graceful degradation are highly desirable features of marine robots. In this regard, it is noted that "unexpected UUV changes include instrument failure, loss of communications with a collaborative robot (or operator), inability to profile the ocean floor, problems with thrusters or control fins, greater than expected energy consumption, etc." [68].

Finally, clothing made of sea urchin-inspired skins might be a really interesting direction to go into. We believe that the main inspiration of sea urchins for roboticists is not the shape, tests (armor plate skeleton), or the algal-scrapping jaw-apparatus of echinoids, but their skin composed of multiple weakly linked, semi-independent sensory-motor units. A piece of clothing with such an echinoid-inspired skin would open up unique extensions of human capabilities, especially since the intelligence of such an echinoid-skin overall would be diametrically opposite to ours.

\section{Possible Limitations}

While we believe that robotic designs based on echinoids are highly promising, there are a few limitations of the echinoid body plan worth mentioning (Table 1).

Table 1. Advantages and disadvantages of envisioned sea urchin-based robot designs.

\begin{tabular}{cccc}
\hline Advantage & Reason & Disadvantage & Reason \\
\hline $\begin{array}{c}\text { Graceful degradation in } \\
\text { the face of damage. }\end{array}$ & $\begin{array}{c}\text { Skin-based elements } \\
\text { semi-autonomous. }\end{array}$ & Slow speed & $\begin{array}{c}\text { Difficulties in coordinating } \\
\text { semi-autonomous elements quickly. }\end{array}$ \\
\hline Scalability & $\begin{array}{c}\text { Skin-based elements } \\
\text { semi-autonomous. }\end{array}$ & $\begin{array}{c}\text { Limited maximum size } \\
\text { numbers of semi-autonomous } \\
\text { elements. }\end{array}$ \\
\hline Ease of programming. & $\begin{array}{c}\text { Need to optimize a limited } \\
\text { number of elements. }\end{array}$ & - & - \\
\hline
\end{tabular}




\subsection{Restriction to Marine Environments}

Echinoids, like all other echinoderms, are restricted to marine habitats; no terrestrial or freshwater-living echinoderms are known. This is most likely due to the ambulacral system of echinoderms, i.e., a hydraulic system filled with filtered seawater. This system would not work in dry or freshwater environments. Any robotic implementation of an echinoid motor system, even if so close to biology as to use a hydraulic system, would be unlikely to depend on uptake of seawater. The restriction of echinoderms to the ocean is hence not a problem likely to carry over to robotics and neuromorphic engineering.

\subsection{Slow Speed}

In sea urchins, the length of the tube feet is small in relation to the body size of the animal, and this likely limits their locomotory speed. It was argued "that the scaling of sea urchin locomotion may follow similar laws to those of legged animals, for which locomotor performance increases with size on horizontal surface, while their relative cost of locomotion increases with body size on inclined surfaces" [69]. The slow movement of these animals might be limited by the way they are built from a large number of small, semi-independent units, and this limitation might carry over to robots inspired by echinoids. There are still multiple applications of robots in which speed is not critical, which would be the right applications for echinoid-inspired robots.

\subsection{Limited Size}

With a modest diameter of only 30 centimeters, the largest currently known sea urchin is the deep-sea species Sperosoma giganteum. Does the de-centralized way of coordinating sea urchin locomotion also limit the maximum size of these animals? This is quite possible, while the use of a hydraulic system could also contribute to the limited maximum size. If the latter issue was limiting, a different technological implementation of the locomotory system would alleviate the problem (while maintaining the principle of using multiple semi-independent sensory-motor units). If indeed some yet unknown scaling law limits the number of semi-independent sensor-motor units which can successfully be coordinated, the size limitation will carry over to robotic implementations. The rather modest upper limit on echinoid size should be kept in mind when designing echinoid-inspired robots.

\section{Summary}

In summary, we advocate that the robotics community look at the biology of sea urchins for inspiration of new robot designs. We emphasize the semi-autonomous functioning of spines, pedicellariae, and tube feet, and the local sensory-motor integration in tube feet. The principles derived from sea urchin biology should allow the design of small, possibly swarming robots involved in non-time-critical tasks, but with a high tolerance for maintaining function when partially damaged. Possible examples would be robots involved in building or vehicle inspection and repair. Sea urchin skin-inspired clothing would be another interesting option.

Author Contributions: This review was conceptualized by K.M.S. and written, reviewed and edited by both K.M.S. and G.A.B.

Funding: This research received funding from the University of Reading to cover the costs of publication.

Acknowledgments: We thank colleagues at the Marine Science Institute of the University of the Philippines, at People and the Sea and at the 2014 Telluride Workshop in Neuromorphic Engineering for inspiring discussion. We also thank the University of Reading for contributions towards publication costs.

Conflicts of Interest: The authors declare no conflict of interest. 


\section{References}

1. Allen, P.L. Feeding behaviour of Asterias rubens (L.) on soft bottom bivalves: A study in selective predation. J. Exp. Mar. Biol. Ecol. 1983, 70, 79-90. [CrossRef]

2. Byrne, M.; Fontaine, A.R. The feeding behaviour of Florometra serratissima (Echinodermata: Crinoidea). Can. J. Zool. 1981, 59, 11-18. [CrossRef]

3. Arendt, D.; Tosches, M.A.; Marlow, H. From nerve net to nerve ring, nerve cord and brain-evolution of the nervous system. Nat. Rev. Neurosci. 2016, 17, 61-72. [CrossRef] [PubMed]

4. Smith, J. On the nervous system of the starfish Marthasterias glacialis (L.). Philos. Trans. R. Soc. Lond. B Biol. Sci. 1937, 227, 111-173. [CrossRef]

5. Mashanov, V.S.; Zueva, O.R.; Heinzeller, T.; Aschauer, B.; Naumann, W.W.; Grondona, J.M.; Cifuentes, M.; Garcia-Arraras, J.E. The central nervous system of sea cucumbers (Echinodermata: Holothuroidea) shows positive immunostaining for a chordate glial secretion. Front. Zool. 2009, 6, 11. [CrossRef] [PubMed]

6. Lowe, C.J.; Wray, G.A. Radical alterations in the roles of homeobox genes during echinoderm evolution. Nature 1997, 389, 718-721. [CrossRef] [PubMed]

7. Sumrall, C.D.; Wray, G.A. Ontogeny in the fossil record: Diversification of body plans and the evolution of "aberrant" symmetry in Paleozoic echinoderms. Paleobiology 2007, 33, 149-163. [CrossRef]

8. Mooi, R.; David, B. Radial symmetry, the anterior/posterior axis, and echinoderm Hox genes. Annu. Rev. Ecol. Evol. Syst. 2008, 39, 43-62. [CrossRef]

9. Ziegler, A.; Faber, C.; Mueller, S.; Bartolomaeus, T. Systematic comparison and reconstruction of sea urchin (Echinoidea) internal anatomy: A novel approach using magnetic resonance imaging. BMC Biol. 2008, 6, 33. [CrossRef] [PubMed]

10. Saucède, T.; Mooi, R.; David, B. Combining embryology and paleontology: Origins of the anterior-posterior axis in echinoids. Comptes. Rendus. Palevol. 2003, 2, 399-412. [CrossRef]

11. Barras, C.G. Morphological innovation associated with the expansion of atelostomate irregular echinoids into fine-grained sediments during the Jurassic. Palaeogeogr. Palaeoclimatol. Palaeoecol. 2008, 263, 44-57. [CrossRef]

12. Hejnol, A.; Lowe, C.J. Embracing the comparative approach: How robust phylogenies and broader developmental sampling impacts the understanding of nervous system evolution. Philos. Trans. R. Soc. B Biol. Sci. 2015, 370, 20150045. [CrossRef] [PubMed]

13. Burke, R.D.; Angerer, L.M.; Elphick, M.R.; Humphrey, G.W.; Yaguchi, S.; Kiyama, T.; Liang, S.; Mu, X.; Agca, C.; Klein, W.H.; et al. A genomic view of the sea urchin nervous system. Dev. Biol. 2006, 300, 434-460. [CrossRef] [PubMed]

14. Díaz-Balzac, C.A.; Lázaro-Peña, M.I.; Vázquez-Figueroa, L.D.; Díaz-Balzac, R.J.; García-Arrarás, J.E. Holothurian nervous system diversity revealed by neuroanatomical analysis. PLoS ONE 2016, 11, e0151129. [CrossRef] [PubMed]

15. Weber, W.; Grosmann, M. Ultrastructure of the basiepithelial nerve plexus of the sea urchin, Centrostephanus longispinus. Cell Tissue Res. 1977, 175, 551-562. [CrossRef] [PubMed]

16. Mashanov, V.S.; Zueva, O.R.; Garcia-Arraras, J.E. Organization of glial cells in the adult sea cucumber central nervous system. Glia 2010, 58, 1581-1593. [CrossRef] [PubMed]

17. Märkel, K.; Röser, U. Functional anatomy of the valves in the ambulacral system of sea urchins (Echinodermata, Echinoida). Zoomorphology 1992, 111, 179-192. [CrossRef]

18. Santos, R.; Hennebert, E.; Coelho, A.V.; Flammang, P. The echinoderm tube foot and its role in temporary underwater adhesion. In Functional Surfaces in Biology; Springer: Dordrecht, The Netherlands, 2009; pp. 9-41.

19. Hennebert, E.; Haesaerts, D.; Dubois, P.; Flammang, P. Evaluation of the different forces brought into play during tube foot activities in sea stars. J. Exp. Biol. 2010, 213, 1162-1174. [CrossRef] [PubMed]

20. Santos, R.; Flammang, P. Morphology and tenacity of the tube foot disc of three common European sea urchin species: A comparative study. Biofouling 2006, 22, 173-186. [CrossRef] [PubMed]

21. Graham, J.B. Ecological and evolutionary aspects of integumentary respiration: Body size, diffusion, and the invertebrata. Am. Zool. 1988, 28, 1031-1045. [CrossRef]

22. Lesser, M.P.; Carleton, K.L.; Bottger, S.A.; Barry, T.M.; Walker, C.W. Sea urchin tube feet are photosensory organs that express a rhabdomeric-like opsin and PAX6. Proc. R. Soc. B Biol. Sci. 2011, 278, 3371-3379. [CrossRef] [PubMed] 
23. Díaz-Balzac, C.A.; Abreu-Arbelo, J.E.; García-Arrarás, J.E. Neuroanatomy of the tube feet and tentacles in Holothuria glaberrima (Holothuroidea, Echinodermata). Zoomorphology 2010, 129, 33-43. [CrossRef] [PubMed]

24. Mooi, R. Non-respiratory podia of clypeasteroids (Echinodermata, Echinoides): II. Diversity. Zoomorphology 1986, 106, 75-90. [CrossRef]

25. Santos, R.; Gorb, S.; Jamar, V.; Flammang, P. Adhesion of echinoderm tube feet to rough surfaces. J. Exp. Biol. 2005, 208, 2555-2567. [CrossRef] [PubMed]

26. McClintock, J.B.; Baker, B.J.; Slattery, M.; Hamann, M.; Kopitzke, R.; Heine, J. Chemotactic tube-foot responses of a spongivorous sea star Perknaster fuscus to organic extracts from antarctic sponges. J. Chem. Ecol. 1994, 20, 859-870. [CrossRef] [PubMed]

27. Young, C.M.; Tyler, P.A.; Emson, R.H.; Gage, J.D. Perception and selection of macrophyte detrital falls by the bathyal echinoid Stylocidaris lineata. Deep Sea Res. Part I Oceanogr. Res. Pap. 1993, 40, 1475-1486. [CrossRef]

28. Ullrich-Lüter, E.M.; Dupont, S.; Arboleda, E.; Hausen, H.; Arnone, M.I. Unique system of photoreceptors in sea urchin tube feet. Proc. Natl. Acad. Sci. USA 2011, 108, 8367-8372. [CrossRef] [PubMed]

29. Agca, C.; Elhajj, M.C.; Klein, W.H.; Venuti, J.M. Neurosensory and neuromuscular organization in tube feet of the sea urchin Strongylocentrotus purpuratus. J. Comp. Neurol. 2011, 519, 3566-3579. [CrossRef] [PubMed]

30. Al-Wahaibi, M.K.; Claereboudt, M.R. Extraocular vision in the sea urchin Diadema setosum. Mar. Freshw. Behav. Physiol. 2017, 50, 31-40. [CrossRef]

31. Campbell, A.C.; Laverack, M.S. The responses of pedicellariae from Echinus esculentus (L.). J. Exp. Mar. Biol. Ecol. 1968, 2, 191-214. [CrossRef]

32. Florey, E.; Cahill, M.A.; Rathmayer, M. Excitatory actions of GABA and of acetylcholine in sea urchin tube feet. Comp. Biochem. Physiol. Part C Comp. Pharmacol. 1975, 51, 5-12. [CrossRef]

33. Berrios, A.; Brink, D.; del Castillo, J.; Smith, D.S. Some properties of the action potentials conducted in the spines of the sea urchin Diadema antillarum. Comp. Biochem. Physiol. A Comp. Physiol. 1985, 81, 15-23. [CrossRef]

34. Peters, B.H. The innervation of spines in the sea-urchin Echinus esculentus L. Cell Tissue Res. 1985, 239, 219-228. [CrossRef]

35. Santos, R.; Haesaerts, D.; Jangoux, M.; Flammang, P. The tube feet of sea urchins and sea stars contain functionally different mutable collagenous tissues. J. Exp. Biol. 2005, 208, 2277-2288. [CrossRef] [PubMed]

36. Birenheide, R.; Tamori, M.; Motokawa, T.; Ohtani, M.; Iwakoshi, E.; Muneoka, Y.; Fujita, T.; Minakata, H.; Nomoto, K. Peptides controlling stiffness of connective tissue in sea cucumbers. Biol. Bull. 1998, 194, 253-259. [CrossRef] [PubMed]

37. Yamada, A.; Tamori, M.; Iketani, T.; Oiwa, K.; Motokawa, T. A novel stiffening factor inducing the stiffest state of holothurian catch connective tissue. J. Exp. Biol. 2010, 213, 3416-3422. [CrossRef] [PubMed]

38. Motokawa, T.; Fuchigami, Y. Coordination between catch connective tissue and muscles through nerves in the spine joint of the sea urchin Diadema setosum. J. Exp. Biol. 2015, 218, 703-710. [CrossRef] [PubMed]

39. Díaz-Balzac, C.A.; Santacana-Laffitte, G.; San Miguel-Ruíz, J.E.; Tossas, K.; Valentín-Tirado, G.; Rives-Sánchez, M.; Mesleh, A.; Torres, I.I.; García-Arrarás, J.E. Identification of nerve plexi in connective tissues of the sea cucumber Holothuria glaberrima by using a novel nerve-specific antibody. Biol. Bull. 2007, 213, 28-42. [CrossRef] [PubMed]

40. Mohd Jani, J.; Leary, M.; Subic, A.; Gibson, M.A. A review of shape memory alloy research, applications and opportunities. Mater. Des. 2014, 56, 1078-1113. [CrossRef]

41. Coppard, S.E.; Kroh, A.; Smith, A.B. The evolution of pedicellariae in echinoids: An arms race against pests and parasites. Acta Zool. 2012, 93, 125-148. [CrossRef]

42. Cobb, J.L.S. The fine structure of the pedicellariae of Echinus esculentus (L.). J. R. Microsc. Soc. 1968, 88, 223-233. [CrossRef]

43. Jangoux, M.; Lawrence, J.M. Echinoderm Studies Volume 1; Balkema; CRC Press: Boca Raton, FL, USA, 1983.

44. Smith, D.P.B.; Bullock, T.H. Model nerve net can produce rectilinear, non-diffuse propagation as seen in the skin plexus of sea urchins. J. Theor. Biol. 1990, 143, 15-40. [CrossRef]

45. Bullock, T.H. Comparative aspects of superficial conduction systems in echinoids and asteroids. Am. Zool. 1965, 5, 545-562. [CrossRef] [PubMed]

46. Lees, D.C.; Carter, G.A. The covering response to surge, sunlight, and ultraviolet light in Lytechinus Anamesus (Echinoidea). Ecology 1972, 53, 1127-1133. [CrossRef] 
47. James, D.W. Diet, movement, and covering behavior of the sea urchin Toxopneustes roseus in rhodolith beds in the Gulf of California, México. Mar. Biol. 2000, 137, 913-923. [CrossRef]

48. Dumont, C.P.; Drolet, D.; Deschênes, I.; Himmelman, J.H. Multiple factors explain the covering behaviour in the green sea urchin, Strongylocentrotus droebachiensis. Anim. Behav. 2007, 73, 979-986. [CrossRef]

49. Barrett, G.; Revell, D.; Harding, L.; Mills, I.; Jorcin, A.; Stiefel, K.M. Tool use by four species of Indo-Pacific sea urchins. bioRxiv 2018, 347914. [CrossRef]

50. Brothers, C.; Smith, K.; Amsler, M.; Aronson, R.; Singh, H.; McClintock, J. Covering behavior of deep-water echinoids in Antarctica: Possible response to predatory king crabs. Mar. Ecol. Prog. Ser. 2016, 553, $155-162$. [CrossRef]

51. Amato, K.R.; Emel, S.L.; Lindgren, C.A.; Sullan, K.M.; Wright, P.R.; Gilbert, J.J. Covering behavior of two co-occurring Jamaican sea urchins: Differences in the amount of covering and selection of covering material. Bull. Mar. Sci. 2008, 82, 255-261.

52. Belleza, D.; Abao, R.; Taguba, C.; Dy, D. Effects of UV-C on the masking behavior of the green urchin Salmacis sphaeroides (Linnaeus, 1758). Philipp. Sci. 2013, 34-43.

53. Pinckney, J.L.; Micheli, F. Microalgae on seagrass mimics: Does epiphyte community structure differ from live seagrasses? J. Exp. Mar. Biol. Ecol. 1998, 221, 59-70. [CrossRef]

54. St Amant, R.; Horton, T.E. Revisiting the definition of animal tool use. Anim. Behav. 2008, 75, 1199-1208. [CrossRef]

55. Mao, S.; Dong, E.; Xu, M.; Jin, H.; Li, F.; Yang, J. Design and development of starfish-like robot: Soft bionic platform with multi-motion using SMA actuators. In Proceedings of the IEEE Conference on Robotics and Biomimetics (ROBIO), Shenzhen, China, 12-14 December 2013; pp. 91-96.

56. Prihastono, P.; Wicaksono, H.; Anam, K.; Effendi, R.; Adji, I.; Kuswadi, S.; Jazidie, A.; Sampei, M. Autonomous five legs robot navigation in cluttered environment using fuzzy q-learning and hybrid coordination node. In Proceedings of the IEEE Conference on 2009 ICCAS-SICE, Fukuoka, Japan, 18-21 August 2009; pp. 2871-2874.

57. Watanabe, W.; Suzuki, S.; Kano, T.; Ishiguro, A. Moving right arm in the right place: Ophiuroid-inspired omnidirectional robot driven by coupled dynamical systems. In Proceedings of the IEEE/REJ Conference on Intelligent Robots and Systems, San Francisco, CA, USA, 25-30 September 2011; pp. 1895-1900.

58. He, J.; Xu, L.; Song, X.; Luo, M.; Chu, J. The driving mechanism research of six unit soft robots. In Proceedings of the IEEE Conference on Robotics, Automation and Mechatronics (RAM), Shenzhen, China, 12-14 December 2013; pp. 79-83.

59. Bell, M.A.; Pestovski, I.; Scott, W.; Kumar, K.; Jawed, M.K.; Paley, D.A.; Majidi, C.; Weaver, J.C.; Wood, R.J. Echinoderm-inspired tube feet for robust robot locomotion and adhesion. IEEE Robot. Autom. Lett. 2018, 3 , 2222-2228. [CrossRef]

60. Sadeghi, A.; Beccai, L.; Mazzolai, B. Design and development of innovative adhesive suckers inspired by the tube feet of sea urchins. In Proceedings of the IEEE Conference on Biomedical Robotics and Biomechatronics (BioRob), Rome, Italy, 24-27 June 2012; pp. 617-622.

61. Ocampo-Jiménez, J.; Muñoz-Meléndez, A.; Rodríguez-Gómez, G. Extending a spherical robot for dealing with irregular surfaces: A sea urchin-like robot. Adv. Robot. 2014, 28, 1475-1485. [CrossRef]

62. Foxe, J.J.; Wylie, G.R.; Martinez, A.; Schroeder, C.E.; Javitt, D.C.; Guilfoyle, D.; Ritter, W.; Murray, M.M. Auditory-somatosensory multisensory processing in auditory association cortex: An fMRI study. J. Neurophysiol. 2002, 88, 540-543. [CrossRef] [PubMed]

63. Beauchamp, M.S.; Argall, B.D.; Bodurka, J.; Duyn, J.H.; Martin, A. Unraveling multisensory integration: Patchy organization within human STS multisensory cortex. Nat. Neurosci. 2004, 7, 1190-1192. [CrossRef] [PubMed]

64. Lakatos, P.; Chen, C.-M.; O'Connell, M.N.; Mills, A.; Schroeder, C.E. Neuronal oscillations and multisensory interaction in primary auditory cortex. Neuron 2007, 53, 279-292. [CrossRef] [PubMed]

65. Engel, A.K.; Fries, P.; Singer, W. Dynamic predictions: Oscillations and synchrony in top-down processing. Nat. Rev. Neurosci. 2001, 2, 704-716. [CrossRef] [PubMed]

66. Wilkie, I.C. Autotomy as a prelude to regeneration in echinoderms. Microsc. Res. Tech. 2001, 55, 369-396. [CrossRef] [PubMed] 
67. Arrichiello, F.; Liu, D.N.; Yerramall, S.; Pereira, A.; Das, J.; Mitra, U.; Sukhatme, G. Effects of underwater communication constraints on the control of marine robot teams. In Proceedings of the IEEE Conference on Robotic Communication and Coordination, Odense, Denmark, 31 March-2 April 2009; pp. 1-8.

68. Seto, M.L.; Paull, L.; Saeedi, S. Marine Robot Autonomy; Springer: New York, NY, USA, 2013. [CrossRef]

69. Domenici, P.; Gonzlez-Caldern, D.; Ferrari, R.S. Locomotor performance in the sea urchin Paracentrotus lividus. J. Mar. Biol. Assoc. UK 2003, 83, 285-292. [CrossRef]

(C) 2018 by the authors. Licensee MDPI, Basel, Switzerland. This article is an open access article distributed under the terms and conditions of the Creative Commons Attribution (CC BY) license (http:/ / creativecommons.org/licenses/by/4.0/). 